\title{
Determination of Gd (III) Concentration by Voltammetry and Its Usage as a Learning Module for Chemistry Student
}

\author{
Santhy Wyantuti ${ }^{1, *}$, Wina R. Oktaviani ${ }^{1}$, Diana Hendrati ${ }^{1}$, Yeni Wahyuni Hartati ${ }^{1}$ \\ and Lena Rahmidar ${ }^{2}$
}

${ }^{1}$ Department of Chemistry, University of Padjadjaran, Jl Raya Bandung Sumedang KM.21, West Java 45363

${ }^{2}$ ARS University, Jl Sekolah Internasional Antapani, Bandung 40291

*Corresponding author. Email: santhy.wyantuti@ unpad.ac.id

\begin{abstract}
Gadolinium is a rare earth metal that has similar properties as other rare earth metals, making it difficult to separate Gadolinium from the others. Gadolinium has been extracted from Erath's crust in the form of their minerals, such as monazite and gadolinite. Gadolinium is widely used for applications in various fields, including medicine and chemical industries, and thus its concentration in the environment is important to note. Generally, the concentration of gadolinium is measured by using XRF, ICP-MS, and ICP-AES methods. However, this method has several drawbacks, such as the high cost of equipment and maintenance. Therefore, an efficient alternative method to determine gadolinium concentration is needed, such as voltammetry. The purpose of this study was to determine the concentration of gadolinium utilizing Differential Pulse Voltammetry (DPV) using acetonitrile as an organic solvent. In addition to the voltammetry method, the Box-Behnken experimental design method was used. The use of the BoxBehnken experimental design aims to see the optimal conditions from the current measurement results. The results of optimum conditions were modulation amplitude of $0.10 \mathrm{~V}$, deposition potential of $-1.328 \mathrm{~V}$, and deposition time of 64.65 seconds. By using the optimum condition, we achieved the recovery of $91.28 \%$, the accuracy of $84.23 \%$, precision of $94.43 \%$, the detection limit of $3.27 \mathrm{mg} / \mathrm{L}$, and the quantitation limit of $10.91 \mathrm{mg} / \mathrm{L}$. The recommended concentration range of $\mathrm{Gd}$ in the sample was from 15.0 to $35.0 \mathrm{mg} / \mathrm{L}$. The result of this research was then applied as a learning module for chemistry students in the undergraduate level at the Department of Chemistry, University of Padjadjaran.
\end{abstract}

Keywords: Rare earth elements, gadolinium, differential pulse voltammetry, learning module.

\section{INTRODUCTION}

Indonesia has a lot of minerals that contain rare earth elements, including gadolinium. Gadolinium $(\mathrm{Gd})$ is a rare earth element in the middle of the lanthanide series, which is stable in the ionic form with $a+3$ valence $[1$, 2]. Research on the determination of gadolinium concentration has actually been carried out, for example by using ICP-MS which distinguishing the mass of an isotope of an element. In addition, there is also the ICPOES method, which is an analysis based on the detection by atomizing an element by emitting light using certain wavelengths $[3,4]$. This method has high sensitivity, but it has drawbacks where the use of the ICP method is relatively difficult to perform, and the cost is relatively high, so that an alternative, efficient, and simple but sensitive method is required, namely by using voltammetry. The voltammetry method is an electrochemical analysis technique based on the measurement of electric current as a function of measuring the electric potential in electrolysis cells. The voltammetry method has many advantages such as simple procedure, allows simultaneous analysis, and a good detection limit $[5,6]$.

The use of organic solvents as a supporting electrolyte solution in metal electrodeposition continues to grow and attracts research interest because it provides an alternative pathway to electrochemical processes. Organic solvents have the ability to dissolve metals compared to water solvents. Acetonitrile is one of the most widely used organic solvents for electrochemical studies due to a wide potential range and high dielectric constant. As a result, acetonitrile can dissolve electrolyte salts and also be mixed with ionic liquids to 
achieve very high ionic conductivity in the metal ion electrodeposition $[7,8]$.

In order to obtain the optimum conditions for $\mathrm{Gd}$ measurement, a Box-Behnken experimental design was used. Box-Behnken is a model that can determine parameters to optimize response. In addition, the BoxBehnken experimental design was used to shorten the analysis time. The measurement parameters to maximize the maximum current response were amplitude modulation, deposition potential, and deposition time. The determination of these measurement parameters was done to minimize reagent usage and shorter the analysis duration $[9,10]$. In this study, a differential pulse voltammetry (DPV) determination of $\mathrm{Gd}$ concentration was developed using acetonitrile solvent with $\mathrm{Pt}$ working electrode, $\mathrm{Pt}$ auxiliary electrode, and dry type of $\mathrm{Ag} / \mathrm{AgCl}$ reference electrode. The results of this study were then used as an Analytical Chemistry teaching material to improve the understanding of undergraduate students in the Chemistry Department.

\section{RESEARCH METHOD}

\subsection{Materials}

The chemicals used in this research were $65 \%$ nitric acid $\left(\mathrm{HNO}_{3}\right.$, Merck), acetonitrile (Merck), and rare earth metal solutions of $\mathrm{Sm}, \mathrm{Eu}, \mathrm{Gd}$, Dy and also $\mathrm{Gd}_{2} \mathrm{O}_{3}$ 99.9\% purity that were purchased from Aldrich. Ultrapure water was used throughout the experiments for dilution and as a solvent.

\subsection{Method}

\subsubsection{The Box-Behnken Experimental Design}

A $10 \mathrm{~mL}$ of $15.0 \mathrm{mg} / \mathrm{L} \mathrm{Gd}$ solution in acetonitrile was pipetted and poured into the voltammetry cell and analyzed using the Box-Behnken experimental design using 3 parameters, namely deposition potential, deposition time, and amplitude modulation. The BoxBehnken experimental design used 3 levels of parameters $(-1,0,+1)$ with 15 measurements.

\subsubsection{Calibration Curve}

A $10 \mathrm{~mL}$ of $15.0 \mathrm{mg} / \mathrm{L} \mathrm{Gd}$ solution was pipetted and poured into the voltammetry cell. The DPV measurement was carried out with the Pt working electrode, using the optimum $\mathrm{Gd}$ conditions as a result of the Box-Behnken experimental design. The experiments were repeated with $\mathrm{Gd}$ solution of 20.0; $25.0 ; 30.0$; and $35.0 \mathrm{mg} / \mathrm{L}$ to build a calibration curve for $\mathrm{Gd}$ analysis.

\subsubsection{Determination of Samples}

A $10 \mathrm{~mL}$ of $35.0 \mathrm{mg} / \mathrm{L} \mathrm{Gd}$ solution was measured as a standard by DPV using the Pt working electrode with deposition potential range of $-1.328 \mathrm{~V}$ to $+1.00 \mathrm{~V}$, a deposition time of 64.65 seconds, scanning rate of 0.05 $\mathrm{V} / \mathrm{s}$, and the amplitude modulation of $0.10 \mathrm{~V}$. The measurement was repeated 3 times, so that the recovery value could be determined. The method was applied to the Gd samples. These results of experiment were then applied to the class and experimental laboratory in the subject of analytical chemistry.

\section{RESULTS AND DISCUSSION}

\subsection{Experimental Results using Box-Behnken}

The Box-Behnken experimental design is one of the methods used to select the parameters that influence gadolinium analysis. The working electrodes used were the $\mathrm{Pt}$ electrode, the dry type $\mathrm{Ag} / \mathrm{AgCl}$ reference electrode, and the Pt auxiliary electrode.

In this study, the gadolinium solution was diluted in $100 \%$ acetonitrile. Fifteen experiments were carried out using 3 parameters, namely amplitude modulation, deposition potential, and deposition time which were analyzed further using the Minitab 17 software. Based on the pulse generation stage diagram at the time of analysis using DPV, the scan will be carried out from the initial potential (negative) to the final potential (towards the positive direction).

After obtaining the parameters for $\mathrm{Gd}$ analysis, then determining the concentration of $\mathrm{Gd}$ with various values of deposition potential, amplitude modulation and deposition time. The values of deposition potential, amplitude modulation, and deposition time were $-1.0 \mathrm{~V}$, $0.1 \mathrm{~V}$, and 60 seconds, respectively. This analysis resulted in a Gd peak with a high current response.

The Box-Behnken design uses 3 levels, namely the high level (+), the lower level (-), and the middle level (0) which are shown in Table 1. Amplitude modulation can affect the separation and sensitivity of the measurement. Therefore, a large amplitude modulation value will produce a large current response, but it will expand the peak and reduce its potential value. Thus, these parameters may have an effect on gadolinium analysis.

Table 1. Analysis parameters of gadolinium by DPV

\begin{tabular}{lccc}
\hline \multirow{2}{*}{ Parameters } & \multicolumn{3}{c}{ Level } \\
\cline { 2 - 4 } & - & 0 & + \\
\hline Deposition potential (V) & -1.5 & -1.0 & -0.5 \\
Deposition time (seconds) & 40 & 60 & 80 \\
Amplitude modulation (V) & 0.050 & 0.075 & 0.100
\end{tabular}


The current response generated from measurements that have been analyzed based on these 3 levels is 15 measurements. The results of the 15 measurements and the results of the data were processed using Minitab 17. From the results of the current response analysis, the parameters that could significantly influence the measurement of the peak current of gadolinium are if the P-value is $<0.05$. The measurement results yielded the P-value of amplitude modulation, deposition potential, and deposition time were $0.015,0.225$, and 0.174 , respectively. This shows that the parameter which can significantly influence the current measurement is amplitude modulation because of the Pvalue $<0.05$. Meanwhile, the $\mathrm{P}$-value $>0.05$ means that the parameter does not significantly influence the resulting responses.

\subsection{Determination of the Gd Calibration Curve}

The determination of the calibration curve was carried out using the optimum value optimization results from the Box-Behnken design by using acetonitrile as an organic solvent. The $\mathrm{Gd}$ concentration used for making the calibration curve was $15.0 ; 20.0 ; 25.0 ; 30.0$; and $35.0 \mathrm{mg} / \mathrm{L}$. The parameters used were amplitude modulation of $0.100 \mathrm{~V}$, deposition time of 64.65 seconds, and deposition potential of $-1.328 \mathrm{~V}$. Also, other parameters used were a potential range of -1.328 $\mathrm{V}$ to $+1.0 \mathrm{~V}$, scanning rate of $0.05 \mathrm{~V} / \mathrm{s}$, using the dry type Pt working electrode (EDA-Q).

Figure 1 shows the gadolinium peak at a potential of $-0.2272 \mathrm{~V}$ and the resulting current response increases with increasing concentration due to more electroactive analyte ions $\left(\mathrm{Gd}^{3+}\right)$ which will be reduced or deposited on the working electrode due to the increased diffusion current.

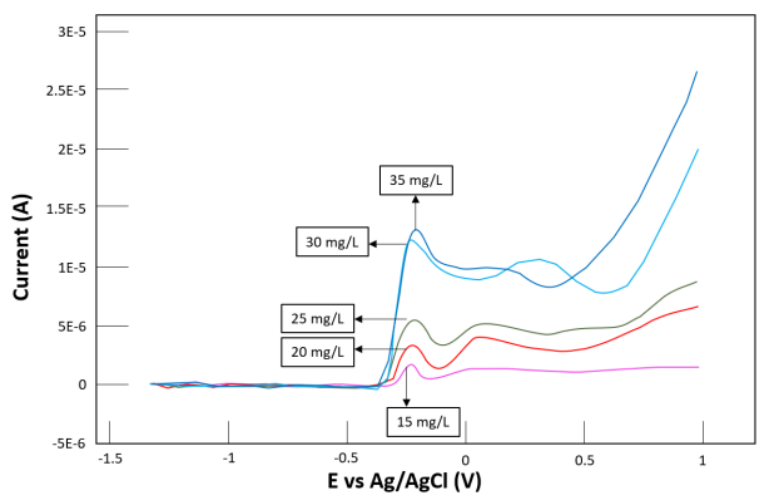

Figure 1. Voltammogram of $\mathrm{Gd}$ with the optimum condition of modulation amplitude of $0.10 \mathrm{~V}$; potential deposition of $-1.328 \mathrm{~V}$; and a deposition time of 64.65 seconds.

Based on the voltammogram in Figure 1, we can see that the greater the concentration, the higher the peak. The current generated by gadolinium with the analysis method using DPV is then plotted and will produce a correlation value (r) at $\mathrm{Gd}$ of 0.9947 . After knowing the correlation value, linear regression calculations will be carried out that will be used to determine the analysis parameters.

\subsection{Detection and Quantitation Limits}

The limit of detection (LoD) is the lowest concentration of analyte from a measurement that can provide a detectable response at a certain level of confidence and can be distinguished from a blank response [11]. This Gd detection limit can be obtained by varying the concentration of 5 concentrations, namely $15,20,25,30$, and $35 \mathrm{mg} / \mathrm{L}$. The obtained detection limit of gadolinium was $3.27 \mathrm{mg} / \mathrm{L}$.

The limit of quantitation (LoQ) is the lowest concentration of analyte in a sample that can be determined with acceptable precision and accuracy under the optimized conditions of the developed method. The LoQ is declared as a concentration by calculating the accuracy of a measurement. The quantitation limit of $\mathrm{Gd}$ calculated from the standard deviation of ten times measurements of blank samples in this research was $10.91 \mathrm{mg} / \mathrm{L}$.

Table 2. The score of Analytical Chemistry course for module application

\begin{tabular}{|c|c|c|c|c|c|}
\hline \multicolumn{6}{|c|}{ Course Score } \\
\hline \multicolumn{2}{|c|}{ Study Program } & \multicolumn{4}{|l|}{ 140210/Kimia } \\
\hline \multicolumn{2}{|c|}{ Sandi MK Sistem } & \multicolumn{4}{|l|}{ 140210_D10B2104_02 } \\
\hline \multicolumn{2}{|c|}{ Course } & \multicolumn{4}{|l|}{ [D10B.2104] Analytical Chemistry } \\
\hline \multicolumn{2}{|c|}{ Semester } & \multicolumn{4}{|l|}{20192} \\
\hline No. & Student No. & Student Name & Mid-test & Final-test & Final Score \\
\hline 1 & '140210170099 & Annas Nursyahid & 60 & 72 & 69 \\
\hline & 140210190050 & Yusrina Imani & 65 & 85 & 74 \\
\hline 3 & 140210190052 & Ayudiah Rizki Utami & 80 & 80 & 80 \\
\hline & '140210190054 & Syifa Fadhilah Faza Hermanto & 80 & 80 & 77 \\
\hline 5 & 140210190058 & Yuristian Diasasmita & 40 & 70 & 62 \\
\hline 6 & '140210190060 & Petricia Hendriana & 72.5 & 72 & 72 \\
\hline 7 & '140210190062 & Dinda Tiara Sitompul & 57.5 & 80 & 70 \\
\hline 8 & '140210190064 & Yulia Fajrina & 70 & 80 & 77 \\
\hline 9 & '140210190066 & Mario Laurent Situmorang & 45 & 80 & 68 \\
\hline 10 & '140210190068 & Syafrul Azid & 67.5 & 80 & 73 \\
\hline 11 & '140210190070 & Ardanari Wahyu Waardhani & 75 & 80 & 80 \\
\hline 12 & '140210190072 & jordi zahra & 70 & 80 & 74 \\
\hline 13 & '140210190074 & Hanifah Ayu Wulansari & 47.5 & 80 & 69 \\
\hline 14 & '140210190076 & Dea fauziah fitri & 67.5 & 85 & 75 \\
\hline 15 & '140210190078 & Dinda Dede Nabila & 57.5 & 76 & 69 \\
\hline 16 & '140210190080 & Meri Wulandari & 62.5 & 78 & 71 \\
\hline 17 & '140210190082 & Fany Yasintha & 67.5 & 80 & 73 \\
\hline 18 & '140210190084 & Artery Syahidillah & 70 & 78 & 73 \\
\hline 19 & '140210190086 & Dian Anggraeni Dewi & 70 & 78 & 73 \\
\hline 20 & \begin{tabular}{|l|}
140210190088 \\
\end{tabular} & Halimah Tussa'diah & 62.5 & 78 & 71 \\
\hline 21 & '140210190090 & Luthfia Sofi NF & 70 & 80 & 74 \\
\hline 22 & '140210190092 & Rifnida Zulfa Akmalia & 27.5 & 75 & 60 \\
\hline 23 & '140210190094 & Hannah Amelia & 27.5 & 76 & 60 \\
\hline
\end{tabular}

\subsection{Calculation of Precision and Accuracy}

The accuracy was calculated from the recovery experiments. In order to determine the value of recovery, it was carried out using Gd solution whose concentration was known to be $35 \mathrm{mg} / \mathrm{L}$, and then the analysis was carried out using DPV using Gd optimum conditions, namely amplitude modulation of $0.10 \mathrm{~V}$, deposition time of 64.65 seconds, and deposition potential $-1.328 \mathrm{~V}$. Based on the results of the 
calculation, the recovery percentage of $\mathrm{Gd}$ was $91.28 \%$, with the accuracy of $84.23 \%$. The precision was measured as a variation where the smaller the standard deviation is, the greater the precision. The precision of the measurement of the $\mathrm{Gd}$ was $94.43 \%$. Based on the replicate analysis of blank, we found the detection limit of $3.27 \mathrm{mg} / \mathrm{L}$, and the quantitation limit of $10.91 \mathrm{mg} / \mathrm{L}$. From the linearity of the calibration curve, the concentration range of $\mathrm{Gd}$ in sample should be from 15.0 to $35.0 \mathrm{mg} / \mathrm{L}$.

A learning module for chemistry students at the undergraduate level at the Department of Chemistry, University of Padjadjaran was made from the result of this research. The final test score, in which the learning module was applied, was higher than the mid-test score for almost all students. Therefore, students' score on the Analytical Chemistry test was significantly improved after the application of the module, as shown in Table 2.

\section{CONCLUSION}

In summary, the usage of acetonitrile as a solvent increases the $\mathrm{Gd}$ that can be deposited on the $\mathrm{Pt}$ electrode. The optimum conditions of amplitude modulation, deposition potential, and deposition time for determining $\mathrm{Gd}$ by DPV with the Box-Behnken experimental design were $0.100 \mathrm{~V},-1.328 \mathrm{~V}$, and 64.65 seconds, respectively. By using the optimum condition, we achieved the recovery of $91.28 \%$, the accuracy of $84.23 \%$, precision of $94.43 \%$, the detection limit of 3.27 $\mathrm{mg} / \mathrm{L}$, and the quantitation limit of $10.91 \mathrm{mg} / \mathrm{L}$. The prepared learning module increased the students' score significantly in the Analytical Chemistry course.

\section{ACKNOWLEDGMENTS}

The authors acknowledge the financial support from Padjadjaran University through the Academic Leadership Grant Program and Directorate of Research and Community Service through Superior Research of Higher Education (DRPM-PDUPT) for providing the research fund (No 1827/UN6.3.1/LT/2020).

\section{REFERENCES}

[1] Cotton, F.A., Wilkinson, G., Murillo, C.A. \& Bochmann, M. Advanced Inorganic Chemistry Sixth edition. New York: John Willey \& Son, Inc. ; 2007.

[2] Wyantuti, S., Pratomo, U., Hartati, Y.W., Anggraeni, A., \& Bahti, H.H. Fast and Simultaneous Detection of Sm, Eu, Gd, Tb and Dy using combination of Voltammetry Method and Multivariate Analysis. Res. J. Chem. Environ. 2018;22;302-306.
[3] Bank, T., Roth, E., Tinker, P., \& Granite, E. Analysis of Rare Earth Elements in Geologic Samples using Inductively Coupled Plasma Mass Spectrometry. US DOE Topical Report; 2016.

[4] Chien, N.X., Khai, P.N., Hien, T.D., Nguyen, D., Bot, D.C., Trung, T. Van, Cuc, N.T., Minh, L.H., Thuc, N.V., Ngan, B.T., \& Thuan, D. Van. The Determination of Rare Eart Elements in Geological and Enviromental Samples by Indutictively Coupled Plasma Mass Spectrometry. 2006; VAEC, 217-225.

[5] Wyantuti, S., Pratomo, U., Hartati, Y.W., Hendrati, D., \& Bahti, H.H. Aplication of Experimental Design by Differential Pulse Voltammetry for Determination of Rare Earth Elements as Complexes with diethylenetriaminepentaacetic acid (DTPA). International Journal of Recent Technology and Engineering. 2019; 8. 33-37.

[6] Wyantuti, S., Pratomo, U., Hartati, Y.W., Hendrati, D., \& Bahti, H.H. A study of green electro-analysis conducted by experimental design method for detection of Samarium as complex with diethylenetriaminepentaacetic acid (DTPA). AIP Conference Proceedings. 2018; 2049;030010.

[7] Koverga., V. O. A new potential model for acetonitrile: Insight into the local structure organization. Journal of Molecular Liquids. 2017; 233, 251-261.

[8] Suchacz, B., Wesolowski, M., Yu, F., Wang, X.X., Yang, N., Compton, R.G., Yu, M., Dai, S., Liu, G., Shakil, A.O., \& Lee, W.M. Voltammetric quantitation of acetaminophen in tablets using solid graphite electrodes. Anal. Methods. 2016; 8(16), 3307-3315.

[9] Wiik, H.E. Methods for Analyzing the 12 Run Plackett-Burman Design. Norway: Norwegian University of Science and Technology; 2014.

[10] Bezerra, M.A., Santelli, R.E., Oliveiraa, E.P., Villar, L.S., \& Escaleira, L.A. Response Surface Methodology (RSM) as A Tool for Optimization in Analytical Chemistry. Talanta, 2008; 965-977.

[11] Skoog, D. A., Holler, F. J., \& Crouch, S. R. Instrumental Analysis (Vol. 47). Belmont: Brooks/Cole, Cengage Learning; 2007. 